\title{
A INDISCIPLINA NO ENSINO TÉCNICO - UMA REVISÃO INTEGRATIVA
}

\author{
Luciane Laidmer Lenz ${ }^{1}$ \\ Suzana Feldens Schwertner
}

\begin{abstract}
Resumo: $\mathrm{O}$ presente trabalho tem como objetivo realizar uma revisão integrativa acerca da indisciplina no universo do Ensino Profissional (ou Ensino Técnico). Para o seu desenvolvimento, foi delimitado o âmbito de busca na base de dados do portal eletrônico da Capes (Portal de Periódicos Capes/MEC) no período dos últimos dez anos (2007-2017). Da análise dos trabalhos encontrados, verificou-se que todos os avaliados ressaltam a ocorrência da indisciplina em todos os ambientes escolares. Constatou-se, também, que há pouca produção científica no que se refere especificamente à indisciplina no Ensino Técnico, demandando maiores pesquisas acerca da sua incidência, causas e consequências no processo de ensino e aprendizagem naquele cenário.
\end{abstract}

Palavras-chave: Indisciplina. Ensino Técnico. Ensino Profissional.

\section{INDISCIPLINE IN TECHNICAL EDUCATION - AN INTEGRATIVE REVIEW}

\begin{abstract}
The aim of this work is to develop an integrative research about indiscipline in professional (technical) education universe. For its development, the search scope was delimited to Capes electronic portal databasis (Portal de Periódicos Capes/MEC) along the last ten years. From the data analysis, it was verified that researches highlight the occurrence of indiscipline in all school environments. It was also demonstrated that there is few scientific production regarding specifically the indiscipline in technical education, demanding more research about its incidence, causes and consequences in teaching and learning processes in that education modality.
\end{abstract}

Keywords: Indiscipline. Technical Education. Professional Education.

1 Advogada. Pós-graduada em Direito de Empresa. Pós-Graduanda em Docência para o Ensino Profissional. 


\section{INTRODUÇÃO}

A indisciplina é um problema que está presente em todos os ambientes escolares e causa impactos no processo de ensino e aprendizagem. Do ponto de vista do professor, a indisciplina dificulta o exercício da docência e, do ponto de vista do aluno, é frequentemente relacionado ao fracasso escolar. Muitas são as causas apontadas para a indisciplina e alternativas são buscadas para o manejo das situações que a caracterizam.

O presente trabalho tem como principal objetivo promover uma investigação acerca da indisciplina no âmbito do ensino técnico: sua incidência, causas e a forma como os atores do ambiente escolar trabalham o problema.

Justifica-se o presente trabalho pela necessidade de apurar como a indisciplina tem ocorrido e como tem produzido efeitos no ambiente e no processo de ensinoaprendizagem no âmbito dos cursos profissionais (técnicos).

Neste sentido, realizou-se uma revisão integrativa dos trabalhos de pesquisa realizados acerca da indisciplina especificamente no universo do Ensino Profissional (ou Ensino Técnico), tendo-se como base de dados o portal eletrônico da Capes/ MEC e delimitando-se o período da busca aos últimos 10 (dez) anos, entre 2007 e 2017.

Inicialmente, apresenta-se a metodologia do trabalho, indicando de que modo a revisão integrativa foi utilizada na investigação. Adiante, realiza-se uma introdução acerca do tema da indisciplina, apoiada especialmente no referencial teórico de Júlio Groppa Aquino e Joe Garcia, apresentando e situando o tema. $\mathrm{Na}$ sequência, faz-se a apresentação dos trabalhos selecionados, efetuando a sua análise e a comparação dos resultados daquelas pesquisas. Ao final, as conclusões são apresentadas a partir do trabalho de revisão, apontando para suas limitações e investigações futuras.

\section{METODOLOGIA}

A revisão integrativa é um método de pesquisa que possibilita a integração de dados teóricos e empíricos. Ainda, incorpora diversos propósitos, tais como a definição de conceitos, a revisão de teorias e a análise de problemas metodológicos de determinado assunto (SOUZA et al, 2010, p. 103).

Para a revisão integrativa proposta no presente trabalho, elegeu-se a base de dados do Portal de Periódicos Capes/MEC para a busca de produção científica acerca da indisciplina no Ensino Profissional ou Técnico. A busca foi realizada na base de dados gratuita do portal. O portal eletrônico da Capes foi escolhido em razão da confiabilidade e amplitude de acesso a conteúdos: nacionais e internacionais, na forma de artigos, dissertações e teses.

A fim de delimitar temporalmente a pesquisa, trazendo ao presente somente os mais atuais escritos na área, restringiu-se a busca de trabalhos de pesquisa ao período dos últimos $10(\mathrm{dez})$ anos. 
A primeira busca de trabalhos científicos que embasam a presente revisão foi realizada utilizando-se os indexadores "indisciplina" e "ensino profissional", termos estes utilizados sem a partícula "e". Para esta busca, foram apresentados 112 (cento e doze) resultados.

Foi ainda realizada uma segunda busca, utilizando-se os indexadores "indisciplina" e "ensino técnico", novamente sem o uso da partícula "e", dada a utilização corrente de ambos os termos. Para esta busca, foram apresentados 40 (quarenta) resultados.

A partir da avaliação dos textos localizados, por meio da leitura de seus resumos e de alguns textos na sua íntegra, foram selecionados três exemplares que tratam diretamente sobre o tema pesquisado, sendo dois artigos e uma dissertação de mestrado.

Entre os textos selecionados, um é oriundo de Portugal e os outros dois são originários do Brasil. Optou-se por manter o texto estrangeiro, tendo em vista a oportunidade de a pesquisa verificar a eventual ocorrência de semelhanças e diferenças no trato do tema indisciplina nos diferentes países.

Os textos excluídos ou tratam de maneira muito incidental sobre o tema, como, por exemplo, no artigo intitulado: Os Desafios do Pedagogo na Função Supervisora em uma Instituição de Educação Profissional (CARVALHO, 2014) e no artigo: O Professor Diretor de Turma como Mediador do Processo Ensino-Aprendizagem (TAVARES, 2015), ou meramente apresentavam os indexadores em seus títulos ou em seus resumos, de forma desconexa com o tema do presente trabalho, como nos seguintes exemplos: Entre Faltas e Estrelas: Controle e Disciplina no Processo de Socialização Profissional de Professoras (KNOBAUCH, 2016); O Ensino e a Experiência nas Narrativas de Professoras de Inglês (GUEDES, 2016); Procedimentos dos Professores Relativamente aos Comportamentos de Indisciplina dos Alunos na Aula de Educação Física (GRAÇA, OLIVEIRA, 2016).

\section{INDISCIPLINA: CONCEITUAÇÃO E SITUAÇÃO DO TEMA}

A indisciplina ganhou maior visibilidade a partir do final dos anos 1980, embora não se possa afirmar que o tema, em si, "não habitasse o imaginário pedagógico antes de então" (AQUINO, 2011). Entretanto, embora tenha ocorrido, a partir daquele período, um crescimento no número de obras a trabalharem o assunto, não há entre elas, segundo AQUINO (2011), uma aproximação conceitual.

Dada a imprecisão do termo indisciplina e as múltiplas situações do cotidiano escolar em que ela poderia, em tese, se caracterizar, é muito difícil conceituá-la de forma definitiva e praticamente impossível arrolar previamente todos os atos que a constituiriam.

Aquino, citado por Caraciolo (2010, p. 10), assim se refere ao aspecto da mutabilidade conceitual do termo indisciplina:

O conceito de indisciplina, como toda criação cultural, não é estático, uniforme, nem tampouco universal. Ele se relaciona com o conjunto de 
valores e expectativas que variam ao longo da história, entre as diferentes culturas e numa mesma sociedade.

Diante desta variabilidade conceitual, há na literatura especializada diversas formas de conceituar a indisciplina. Souza (2007, p. 23), de maneira ampla, assim afirma:

$\mathrm{O}$ ato de indisciplina encontra-se ligado ao descumprimento das regras e/ou dos princípios pedagógicos, ditados pelas autoridades dos sistemas de ensino, em suas diversas esferas de competência.

La Taille (1996, p. 10) conceitua disciplina e indisciplina da seguinte maneira:

Se entendermos por disciplina comportamento regidos por um conjunto de normas, a indisciplina poderá se traduzir de duas formas: 1) a revolta contra estas normas; 2) o desconhecimento delas. No primeiro caso, a indisciplina traduz-se por uma forma de desobediência insolente; no segundo, pelo caos dos comportamentos, pela desorganização das relações.

Vê-se, portanto, que a indisciplina diz respeito aos comportamentos não adequados ao regramento aplicável a determinado ambiente, seja por desconhecimento deste regramento, seja pela não concordância com o mesmo.

Garcia (2006, p. 127) refere que a abrangência do que se trata como indisciplina se amplia na medida em que os professores costumam tratar por este nome certos atos que, para alguns autores franceses, seriam chamados incivilidades. As incivilidades, ressalta, seriam transgressões às regras de convívio social, aos pactos sociais que se pressupõe serem conhecidos desde a infância. As incivilidades, portanto, não romperiam, necessariamente, com as regras e programas pedagógicos.

Aquino (1996, p. 40), no seu artigo "A desordem na relação professor-aluno: indisciplina, moralidade e conhecimento", dimensiona a importância do tema da indisciplina, assim referindo:

A indisciplina seria, talvez, o inimigo número um do educador atual, cujo manejo as correntes teóricas não conseguiriam propor de imediato, uma vez que se trata de algo que ultrapassa o âmbito estritamente didático-pedagógico, imprevisto ou até insuspeito no ideário das diferentes teorias pedagógicas. É certo, pois, que a temática disciplinar passou a se configurar enquanto um problema interdisciplinar, transversal à Pedagogia, devendo ser tratado pelo maior número de áreas em torno das ciências da educação. Um novo problema que pede passagem.

O mesmo autor refere, na sua obra "A indisciplina e a escola atual" (1998), que a indisciplina se enquadraria entre os distúrbios de caráter comportamental e, juntamente com o baixo rendimento escolar, representariam duas faces da mesma moeda, geradores do fracasso escolar e das dificuldades para a docência. Entretanto, segundo o autor, as hipóteses normalmente utilizadas para explicar a indisciplina vêm, não raro, revelando preconceitos e ideias falaciosas. Segundo Aquino (1998), três seriam as hipóteses explicativas mais comuns para o fenômeno da indisciplina: $\mathrm{o}$ aluno desrespeitador, o aluno sem limites e o aluno desinteressado. 
A hipótese do aluno desrespeitador normalmente vem apoiada numa ideia de que as escolas da atualidade se tornaram muito permissivas, e que, nas escolas de antigamente, os alunos respeitavam os professores. Entretanto, tal tese é questionada pelo autor no sentido de que os alunos de antigamente não respeitavam seus professores, mas antes os temiam.

A segunda hipótese, do aluno sem limites, igualmente não se sustenta, de acordo com Aquino. Segundo afirma, esta hipótese vem sustentada no argumento de que as crianças de hoje não possuem limites, e que tal seria causado pelos pais, que seriam permissivos. Entretanto, tal hipótese não procederia porque as crianças, desde a mais tenra infância, possuem e estabelecem, mesmo entre si, limites, inclusive de forma bastante restrita.

A terceira hipótese, do aluno desinteressado, apoia-se na premissa de que a escola não é tão atrativa quanto a televisão e outros meios de informação e entretenimento. Segundo o Aquino (1998), esta teoria também mereceria reparos, na medida em que a escola não é um meio de comunicação, nem de entretenimento. A escola é um local de trabalho, de construção de conhecimento, e não só de difusão de informação. Não é, portanto, sequer comparável com os meios de comunicação.

Segundo Aquino (1998), as três hipóteses acima incidiriam em erro ao entender a disciplina como um pré-requisito para a ação pedagógica, quando na verdade a disciplina seria um efeito do cotidiano de sala de aula.

Por seu turno, o Garcia (2006) refere que a indisciplina pode ter dois tipos de causas: externas e internas. As causas externas para a indisciplina escolar estariam relacionadas à violência social e a problemas familiares. As causas internas se refeririam às causas originadas dentro da escola, como o ambiente escolar e o currículo. Segundo Garcia (2013), se o aluno se sente bem na escola e se o currículo da instituição for bom ('valendo a pena ser disciplinado', como mencionado pelo autor), não ocorrerá ou será minimizada a indisciplina.

Tanto Garcia (2006) quanto Aquino (1998) convergem no sentido de provocar uma reflexão acerca de qual o papel do professor frente às situações de indisciplina. Garcia (2006) refere-se à importância de o professor ater-se ao ato de indisciplina, não transportando sentimentos seus ou fatos passados para a resolução de cada situação. Ressalta, ainda, a importância de preservar as pessoas envolvidas no fato, ressaltando que tanto o professor quanto o aluno merecem respeito. Refere, também, a necessidade de 'dar-se um passo adiante', não eternizando o fato indisciplinado, mas sim buscando uma forma de solucioná-lo.

Já Aquino (1998) apresenta quatro princípios éticos para balizarem a atividade do professor, notadamente no que se refere à indisciplina: ater-se ao seu papel pedagógico, não tentando atuar de forma a moralizar hábitos dos alunos; entender a relação professor-aluno como de corresponsabilidade para o sucesso; entender que a sala de aula é o local adequado para resolver os obstáculos; estabelecer regras de convivência (neste aspecto, apresentando o mesmo aconselhamento de Garcia). 
Aquino (1998) apresenta ainda cinco regras éticas do trabalho docente, quais sejam: entender o aluno-problema como um porta-voz das relações estabelecidas em sala de aula; a desidealização do aluno modelo; a fidelidade ao contrato pedagógico; a experimentação de novas estratégias de trabalho; a ideia de que os valores da competência e do prazer devem pautar a atuação em sala de aula.

Ressalte-se, por oportuno, que não é objetivo da disciplina no ambiente escolar a conformação do aluno a um perfil idealizado. Pretende-se, isto sim, que se alcance o bom desempenho do processo de ensino e aprendizagem, propiciando que alunos e escola alcancem o melhor desempenho do ponto de vista pedagógico, bem como que os alunos se transformem em bons cidadãos, devidamente integrados dentro sistema social em que vivem.

Assim, vistas estas considerações acerca do tema da indisciplina, passa-se à apresentação da revisão propriamente dita, realizada no presente trabalho.

\section{INDISCIPLINA NO ENSINO PROFISSIONAL/TÉCNICO: RESULTADOS DA INVESTIGAÇÁO}

A partir da busca por trabalhos de pesquisa acerca do tema da indisciplina no âmbito do ensino profissional/técnico, foram encontradas no portal eletrônico da Capes unicamente três itens diretamente relacionados ao assunto, dois artigos e uma dissertação de mestrado, os quais se passa a apresentar.

\subsection{A indisciplina no Ensino Técnico em Portugal}

\begin{tabular}{|l|l|l|l|}
\hline Autor & Título & Ano de publicação & Classificação \\
\hline COUTO, Vania & Indisciplina na Escola: & 2013 & $\begin{array}{l}\text { Dissertação de } \\
\text { Sofia Lopes Sengo } \\
\text { Freixo de Oliveira }\end{array}$ \\
$\begin{array}{l}\text { Um estudo sobre os } \\
\text { comportamentos de (in) } \\
\text { disciplina de alunos de } \\
\text { cursos profissionais }\end{array}$ & & Sociologia \\
\hline
\end{tabular}

O trabalho intitulado Indisciplina na Escola: Um estudo sobre os comportamentos de (in)disciplina de alunos de cursos profissionais, de Vânia Sofia Lopes Sengo Freixo de Oliveira Couto, publicada no ano de 2013, está relacionada no portal eletrônico da Capes como trabalho de Mestrado em Sociologia.

Segundo a autora, o trabalho realizado teve como objetivos gerais a análise do fenômeno da indisciplina a partir das relações de controle e poder, bem como das relações entre os comportamentos caracterizadores da indisciplina e as práticas pedagógicas dos professores. Pretendeu, ainda, analisar a percepção que os alunos têm em relação aos atos que consideram indisciplina, o papel das famílias na sua prevenção e o papel das punições na sua repressão.

Como objetivo específico, a autora pretendeu avaliar os comportamentos relativos à indisciplina de alunos de cursos de ensino profissional de uma escola 
localizada na cidade de Espinho, em Portugal. A autora justifica que uma das motivações que a levaram a realizar o seu trabalho neste âmbito de pesquisa foi o interesse e a necessidade de entender de que modo os cursos profissionais podem transformar o aluno, tanto no aspecto pedagógico, quanto na questão da cidadania.

Antes de apresentar sua pesquisa, a autora dedica-se à conceituação da indisciplina, bem como à indicação de suas possíveis causas, apontando-as da perspectiva dos alunos e da perspectiva dos professores. Introduz aspectos acerca da educação em Portugal e, adiante, apresenta as características do ensino profissional naquele país. Neste particular, autora refere dois motivos que levam os alunos a frequentarem o ensino técnico: motivações de raiz vocacional e, em menor medida, "[...] o insucesso noutros cursos do Ensino Secundário" (COUTO, 2013, p. 38). Menciona, ainda, que os cursos técnicos têm aumentado muito em número de cursos e em número de alunos em Portugal nos últimos anos e que tem se revelado uma alternativa para a superação das desigualdades sociais presentes naquele país e que se refletem no sistema educacional.

A autora realizou o seu trabalho de pesquisa junto à Escola Profissional de Espinho (Portugal), tendo como participantes 155 (cento e cinquenta e cinco) alunos (59 do sexo masculino e 96 do sexo feminino), todos com idades entre 14 (catorze) e 23 (vinte e três) anos, que frequentam os cursos profissionais de Organização de Eventos, Recepção e Turismo. Todos os participantes foram avaliados dentro do contexto escolar. Participaram, também, da pesquisa, 05 (cinco) professores, com idades entre 28 (vinte e oito) e 47 (quarenta e sete) anos de idade, com experiência de ensino entre 05 (cinco) e 25 (vinte e cinco) anos, além do Diretor e do Diretor Pedagógico da Escola.

Para a coleta de dados, Couto (2013) utilizou-se dos seguintes instrumentos: uma entrevista exploratória, administrada ao Diretor da escola e ao Diretor Pedagógico, contendo questões relativas às suas características profissionais e relativas à indisciplina escolar; uma grade de observação, a ser respondida pela própria observadora e que avalia a postura de alunos e de professores em sala de aula; inquérito aos alunos, com questões relativas à indisciplina; inquérito aos professores, igualmente com questões sobre indisciplina. Foram realizadas as técnicas de análise de conteúdo das entrevistas e de documentos, de observação participante e entrevistas semiestruturadas.

Ao final de seu trabalho, Couto (2013) apresenta os resultados obtidos. Da observação em sala de aula, a primeira consideração feita pela autora refere-se às práticas pedagógicas utilizadas pelos professores, as quais ela julgou satisfatórias. Entendeu, entretanto, que alguns dos professores observados poderiam adaptar as estratégias de ensino ao público-alvo, promover atividades mais variadas, bem como manter uma atitude mais firme e manter mais contato visual com os alunos, a fim de gerir melhor eventuais conflitos.

Em relação aos alunos, Couto (2013) refere que, a partir da observação realizada, não houve incidentes a registrar, considerando a postura dos mesmos satisfatória. Registra, porém, que a maioria das turmas apresenta resultados 
insatisfatórios no que se refere à participação em aula e ao interesse pelas matérias lecionadas.

Do inquérito remetido aos alunos apreendeu-se que estes admitem a existência de um conjunto de atitudes que caracterizam a indisciplina e que atrapalham o professor. O que varia entre os alunos são quais as condutas tidas como indisciplinas e o seu grau de gravidade. Verificou-se ainda que a incidência de registros de indisciplina ocorre em maior percentual entre os indivíduos do sexo masculino, o que seria referendado pela literatura especializada.

Por fim, constatou-se em relação aos alunos que $74,2 \%$ (setenta e quatro vírgula dois por cento) afirmam que há mais regras na escola do que em casa, o que a autora afirma também ser corroborado pela literatura da área e que indicaria a falha de autoridade no seio familiar.

Ainda, segundo a percepção da maioria dos alunos $(65,8 \%)$ demonstrada no inquérito a eles apresentado, existem professores que exigem mais disciplina em sala de aula do que outros. Couto (2013) pondera esta informação com aquela obtida nas entrevistas realizadas, no sentido de que os alunos se comportam de forma diferente em cada aula, a depender do comportamento do professor e às suas estratégias de ensino.

Do inquérito direcionado a cinco professores, Couto (2013) apurou que todos eles declararam que ser professor é gratificante, tendo, porém, quatro deles afirmado que enfrentam dificuldades no exercício da profissão. Sobre o que caracterizaria o perfil de um bom aluno, eles divergiram, tendo um afirmado que tal se caracterizaria a partir de boas notas, dois referiram o bom comportamento e dois afirmaram que nenhuma das respostas era satisfatória. Nenhum dos professores se referiu à assiduidade.

Questionados os professores, todos afirmaram ocorrer situações de indisciplina na escola avaliada. Sobre as suas causas, quatro dos cinco afirmaram que elas têm origem ora no professor, ora no aluno. Para alguns professores, a idade dos alunos, que estão numa fase de transição, pode representar a causa de comportamentos indisciplinados. Questões familiares também foram apontadas como causas de indisciplina.

Questionados sobre quais as medidas que adotam em caso de comportamentos indisciplinados, quatro dos professores informaram que não adotam qualquer das alternativas sugeridas no inquérito (gritar, expulsar o aluno de sala ou ditar as regras) e um deles afirmou que adotava todas as posturas. Diante destas respostas, Couto (2013) conclui que as medidas adotadas dependem do aluno e da situação posta.

Em relação às entrevistas realizadas com o Diretor e o Diretor Pedagógico da Escola, questionado sobre as causas da indisciplina, o Diretor da Escola afirmou que ela tem causas de ordem familiar. Em relação à prevenção da indisciplina, o Diretor afirmou que deve se centrar no professor, no psicólogo e em estratégias realizadas dentro da escola. 
O Diretor Pedagógico, em relação às causas da indisciplina, ressaltou fatores familiares, a idade dos alunos, que estariam em uma "faixa etária turbulenta" (COUTO, 2013, p. 64), e a crise econômico-social. Relativamente à prevenção da indisciplina, apontou hábitos de trabalho e respeito que a escola deve desenvolver e aprimorar com os seus alunos.

Apresentados os dados apurados, Couto (2013) conclui que na escola avaliada apresenta, como em todo o universo escolar, há a incidência de casos de indisciplina. Conclui, ainda, que a indisciplina tem diversas causas, salientando especificamente aquelas inerentes ao professor (de ordem relacional e pedagógica) e as que têm origem no ambiente familiar (falência de autoridade). Apontou, também, que as situações de indisciplina ocorrem mais em relação a indivíduos do sexo masculino do que feminino.

Por fim, Couto (2013) ressalta as limitações do estudo realizado (tamanho da amostra e limitação a um momento no tempo) e afirma que os dados obtidos parecem sugerir que são necessários programas de intervenção eficazes para prevenir a indisciplina no ambiente escolar.

\subsection{A indisciplina no Ensino Técnico no Brasil}

\begin{tabular}{|l|l|l|l|}
\hline Autores & Título & Ano de publicação & Classificação \\
\hline $\begin{array}{l}\text { Ícaro Arcênio } \\
\text { Aguiar Rodrigues } \\
\text { et al. }\end{array}$ & $\begin{array}{l}\text { Como os Docentes de } \\
\text { Cursos Técnicos Integrados } \\
\text { Compartilham a Gestão da } \\
\text { Indisciplina }\end{array}$ & 2017 & Artigo \\
\hline
\end{tabular}

O segundo artigo encontrado a partir da busca realizada para o desenvolvimento do presente trabalho intitula-se Como os Docentes de Cursos Técnicos Integrados Compartilham a Gestão da Indisciplina (RODRIGUES et al, 2017).

O trabalho de pesquisa, publicado em 2017, teve como objetivo investigar como os professores que lecionam para os Cursos Técnicos Integrados ao Ensino Médio no Instituto Federal de Educação, Ciência e Tecnologia da Paraíba Campus Campina Grande fazem a "[...] gestão compartilhada dos comportamentos indisciplinados dos discentes em sala de aula, entre professores e demais setores e agentes educacionais" (p. 171).

Os autores justificam a pesquisa por entender que a indisciplina é uma realidade compartilhada por todos os ambientes escolares e que interfere negativamente na realização do seu objetivo principal, que é o processo de ensino e aprendizagem.

Após realizar uma digressão acerca do tema da indisciplina, os autores apresentam a metodologia do trabalho realizado. Informam que a pesquisa é caracterizada como de campo (pois realizada nas condições em que os eventos 
ocorrem, sem intervenção) e explicativa (pois procura aprofundar os conhecimentos da realidade, visando a identificar os fatores determinantes dos fenômenos).

Para a coleta de dados, foram utilizados questionários de respostas abertas e fechadas, aplicados no segundo semestre de 2012 a 68 (sessenta e oito) professores. O método utilizado para a análise das respostas dos questionários foi o de análise de conteúdo. O objetivo da investigação foi verificar se os professores costumam compartilhar a gestão da indisciplina com outros setores e de que modo ocorre a solicitação de auxílio.

Questionados os professores se estes costumam pedir ajuda para solucionar situações de indisciplina, 54\% (cinquenta e quatro por cento) referiram não solicitar ajuda, 44\% (quarenta e quatro por cento) responderam que sim e $2 \%$ (dois por cento) não responderam. Os autores da pesquisa relacionam a resposta a tal pergunta a outra apresentada, que questionava se os professores se sentiam preparados para lidar com a indisciplina. Para esta questão, 90\% (noventa por cento) responderam positivamente. Entretanto, questionados os professores se possuíam formação para gerenciar a indisciplina, $78 \%$ (setenta e oito por cento) responderam negativamente.

Para os docentes que afirmaram solicitar auxílio na solução de situações de indisciplina foi questionado com que frequência costumavam fazê-lo. A maioria dos professores $(55 \%)$ respondeu que solicita auxílio a outros setores da escola raramente, e outros $21 \%$ (vinte e um por cento) responderam que o fazem eventualmente. Afirmaram sempre pedir apoio a outros setores 4\% (quatro por cento) e pedir apoio na maior parte das vezes outros $4 \%$ (quatro por cento). Não responderam com que frequência pedem auxílio 16\% (dezesseis por cento).

Entre os professores que solicitam auxílio a outros setores/pessoas, a maior parte informou buscar ajuda junto à Coordenação Pedagógica (49\%). Os demais dividem-se na busca de apoio em setores da instituição investigada e apenas $5 \%$ (cinco por cento) afirmam buscar apoio em outros docentes.

Questionados sobre a forma como executam o pedido de auxílio, a maior parcela dos professores (48\%) afirmou solicitar ajuda à auxiliar educacional para chamar outro profissional até a sala e outros 33\% (trinta e três por cento) afirmou ausentar-se da sala para procurar outro setor ou pessoa.

Ao final da sua pesquisa, os autores concluíram que a maioria dos professores não costuma atuar de forma conjunta na gestão da indisciplina e, quando o fazem, isto ocorre para a solução de casos pontuais. Concluíram, ainda, que a Coordenação Pedagógica é o principal órgão para o qual se reportam os professores quando solicitam apoio na gestão de comportamentos indisciplinados.

Por fim, os autores afirmam que os resultados da pesquisa realizada sugerem a realização de novas investigações, especialmente acerca da razão pela qual os professores não costumam procurar auxílio nas questões disciplinares. 
4.3 A indisciplina na perspectiva dos alunos de cursos técnicos

\begin{tabular}{|l|l|l|l|}
\hline Autores & Título & Ano de publicação & Classificação \\
\hline $\begin{array}{l}\text { Ícaro Arcênio } \\
\text { Aguiar Rodrigues }\end{array}$ & $\begin{array}{l}\text { A indisciplina e o } \\
\text { regulamento disciplinar: } \\
\text { percepsões dos estudantes de } \\
\text { cursos técnicos integrados }\end{array}$ & 2015 & Artigo \\
\hline
\end{tabular}

O terceiro artigo encontrado a partir da busca realizada para a realização do presente trabalho intitula-se $A$ indisciplina e o regulamento disciplinar: percepcões dos estudantes de cursos técnicos integrados, da autoria de Icaro Arcênio de Alencar Rodrigues, e foi publicado em dezembro de 2015.

O objetivo do trabalho de pesquisa realizado pelo autor foi investigar o conhecimento dos alunos dos primeiros anos dos Cursos Técnicos Integrados ao Ensino Médio do Instituto Federal da Paraíba - Campus de Campina Grande, acerca do Regimento Disciplinar da instituição.

Antes de apresentar os resultados de sua pesquisa, Rodrigues (2015) faz uma apresentação do tema. Citando dados de pesquisas recentes, informa que 500 (quinhentos) professores entrevistados, 69\% (sessenta e nove por cento) afirmam que a indisciplina é problema basal em sala de aula. Pondera ainda que, mesmo que a indisciplina seja um fator que interfere na rotina escolar, a função da disciplina é questionada como fator que pode ameaçar a boa relação entre aluno e professor.

Para a coleta de dados para a sua pesquisa, Rodrigues (2015) utilizou um questionário de perguntas abertas, remetido para 38 (trinta e oito) alunos do primeiro ano dos cursos técnicos, onde lhes foi questionado, em suma, se conheciam o Regulamento Disciplinar da instituição, se sabiam qual a função do instrumento e se tinham sugestões ou críticas a apresentar.

Segundo dados apurados, 61\% (sessenta e um por cento) dos alunos entrevistados afirmaram conhecer o Regulamento Disciplinar do Instituto Federal de Pernambuco, seja parcial ou totalmente. Os restantes 39 (trinta e nove por cento) afirmaram não conhecer o documento.

Dentre os alunos que afirmaram conhecer o Regulamento Disciplinar, diversas foram as interpretações acerca de qual seria a função daquele instrumento. Assim foram as respostas:

\begin{tabular}{|l|l|}
\hline Percentual & Resposta \\
\hline $41 \%$ & Disciplinar/manter a ordem \\
\hline $18 \%$ & Não respondeu \\
\hline $15 \%$ & Melhorar a convivência \\
\hline $7 \%$ & Organizar e ajudar no funcionamento do Instituto \\
\hline $4 \%$ & Instruir os alunos \\
\hline
\end{tabular}




\begin{tabular}{|l|l|}
\hline Percentual & Resposta \\
\hline $4 \%$ & Apenas conhecer as regras do laboratório \\
\hline $4 \%$ & Conscientizar o aluno do próprio erro \\
\hline $4 \%$ & Orientar os alunos \\
\hline $3 \%$ & Mostrar os deveres dos alunos e professores \\
\hline
\end{tabular}

Neste particular, Rodrigues (2015, p. 93) ressalta que o Regulamento Disciplinar do IFPB do ano de 2011 dispõe, em seu art. $1^{\circ}$, que tem a finalidade de "[...] definir os direitos e deveres, contemplando um código de conduta para a convivência e disciplina".

A terceira questão lançada aos alunos entrevistados foi a possibilidade de apresentar críticas ou propor sugestões ao Regimento Disciplinar. Para tal questionamento, 64\% (sessenta e quatro por cento) dos alunos que afirmou conhecer o Regulamento não apresentaram críticas ou sugestões; $27 \%$ (vinte e sete por cento) afirmaram gostar e concordar com as normas e $9 \%$ (nove por cento), equivalente a um aluno, avaliou que o Regimento não foi aplicado em casos passíveis de punição.

A partir dos dados obtidos, Rodrigues (2015) considerou que os alunos detêm conhecimentos básicos acerca do Regimento Disciplinar da instituição em que estudam, e avalia que a pesquisa realizada abre espaço para outras duas novas investigações: acerca do impacto da metodologia utilizada pelos docentes para a apresentação do Regimento aos alunos e acerca do impacto do conhecimento do Regimento no comportamento dos alunos.

\subsection{Análise e comparaçáo dos resultados}

Os trabalhos analisados apresentam perspectivas de investigação diferentes: o primeiro, de Couto (2013), investiga a indisciplina do ponto de vista de alunos, professores, Direção da Escola e Direção Pedagógica. É, portanto, mais completo do ponto de vista da abrangência dos participantes do estudo. Investiga, também, as causas da indisciplina e como os professores lidam com os comportamentos indisciplinados, sendo igualmente mais abrangente do que os demais trabalhos no que se refere aos aspectos investigados.

A segunda investigação - Rodrigues et al. (2017) - é realizada do ponto de vista somente dos professores, sendo, portanto, mais limitada no aspecto da abrangência. Além disto, a pesquisa realizada não investiga as causas do fenômeno $\mathrm{da}$ indisciplina.

A terceira pesquisa - Rodrigues (2015) - abrange unicamente o ponto de vista dos alunos e limita a sua investigação ao conhecimento que aqueles detêm acerca do Regulamento Disciplinar da instituição em que estudam. 
É de se ressaltar que a segunda e a terceira pesquisas foram realizadas no mesmo ambiente escolar, o que acaba por limitar ainda mais o âmbito de abrangência das conclusões do presente trabalho.

A partir da leitura dos trabalhos avaliados depreende-se que todos referem a indisciplina como um fenômeno que ocorre em todos os ambientes de ensino, afirmando-o seja como premissa para a sua investigação, seja a partir dos resultados apresentados.

É de se considerar, portanto, que sendo um evento reiterado e prejudicial ao processo de ensino e aprendizagem, trata-se a indisciplina de um assunto de grande relevância para o meio docente, merecendo ser analisado.

Outro aspecto importante a referir na análise conjunta dos trabalhos avaliados é que todos realizam as suas pesquisas dentro do ambiente do Ensino Técnico integrado com o Ensino Médio. A partir de tal consideração, poderíamos concluir que se trata de mera coincidência procedimental ou, por outro lado, que a incidência de indisciplina possa ocorrer de forma mais significativa neste cenário, aí desafiando pesquisas. Interessante ressaltar, nesse particular, que os professores ouvidos na pesquisa de Couto (2013) referem a idade dos alunos como uma das possíveis causas para a indisciplina.

Dentre os trabalhos analisados, somente o primeiro (COUTO, 2013) realiza investigação acerca das causas para a indisciplina escolar. Como resultados, aparecem causas diversas, conforme o ponto de vista avaliado: para os alunos, a conduta do professor é determinante do seu comportamento em sala de aula; para a direção da escola e a direção pedagógica, as causas para a indisciplina estariam mais vinculadas a problemas familiares (falha de autoridade) e problemas sociais; do ponto de vista dos professores, a indisciplina tem causas variadas (surgidas do aluno, surgidas do professor, surgidas da família, da idade dos alunos). Verifica-se, portanto, que as causas apuradas estão em consonância com as lições de Garcia (2006), anteriormente apontadas, de natureza interna e externa ao ambiente escolar.

Por outro lado, embora a importância do papel do professor no trato das questões disciplinares, somente os dois primeiros trabalhos se dedicam à investigação das condutas dos professores frente a comportamentos indisciplinados, e o fazem de maneira não aprofundada.

O primeiro dos trabalhos (COUTO, 2013) trata brevemente da questão, apresentando condutas previamente sugeridas, as quais os professores afirmaram praticar ou não. Já o segundo trabalho (RODRIGUES et al, 2017) aprofunda-se no aspecto de o professor buscar ou não apoio em outros setores da escola. Neste particular, apurou que a busca de ajuda ocorre em menos da metade dos professores investigados e, dentre estes, a maioria busca apoio na Coordenação Pedagógica.

Interessante referir os dados apurados no sentido de que somente $5 \%$ (cinco por cento) dos professores afirma buscar apoio em outros docentes, o que, por si só, já poderia sugerir um novo campo de pesquisa e, quiçá, de intervenção de modo a implementar novas condutas na gestão da indisciplina, tomando o espaço 
da docência e de sua elaboração coletiva como um dos modos de discutir sobre o tema.

Em relação ao terceiro trabalho, este investiga o conhecimento dos alunos acerca do Regulamento Disciplinar da escola em que estudam. Embora a pesquisa tenha apurado que a maioria dos alunos diz conhecer o conteúdo e a função do Regulamento, a ausência de elementos a demonstrarem o efetivo conhecimento do documento, a diversidade de respostas à questão do objetivo do instrumento e a ausência de críticas ou sugestões (visto que a única manifestação contrária ao Regimento Disciplinar foi no sentido de reclamar a sua não aplicação quando o entrevistado entendia devido) podem levar à conclusão de que os resultados mereceriam um tratamento mais amplo, demandando, portanto, maiores investigações.

Ainda, cabe ressaltar em relação a esta pesquisa que 18\% (dezoito) por cento dos alunos não responderam ao questionamento sobre qual seria a função do Regulamento Disciplinar. Seria útil avaliar, neste caso, por que os alunos não responderam a tal questionamento: se de fato não sabiam a função do instrumento ou se não enxergam, percebem ou apreendem a função do mesmo.

É de se ressaltar, entretanto, que a pesquisa relacionada ao conhecimento do Regulamento Escolar é importante e se coaduna com as lições de Aquino (1998) e Garcia (2006), que indicam o estabelecimento de regras claras de convivência como fator de redução da indisciplina.

\section{CONCLUSÓES}

A indisciplina é fenômeno presente em todos os ambientes escolares e influencia negativamente o processo de ensino e aprendizagem, prejudicando deveras o professor no exercício da sua função. No caso deste trabalho, a ênfase foi investigar de que modo vem sendo organizadas pesquisas acerca do tema (indisciplina) no âmbito do Ensino Técnico.

Conforme se pode depreender dos trabalhos avaliados, as causas para a indisciplina são várias, sem que haja, entretanto, uma investigação mais profunda ou um consenso demonstrado acerca de o quanto (ou de que forma) cada uma delas é determinante ou quais as mais presentes. Neste sentido, é de se ressaltar, inclusive, que as causas para a indisciplina são vistas de formas diversas pelos diferentes atores do ambiente escolar, em se tratando de Ensino Profissional.

A par disto, não há uma uniformidade de condutas dos professores para lidar com os comportamentos indisciplinados, ou mesmo um preparo profissional para tanto. A isto se seguem as respostas diversas dos professores nas pesquisas realizadas quando questionados sobre como reagem frente aos atos indisciplinados ou se buscam algum tipo de apoio.

Portanto, como um fenômeno tão presente na realidade escolar, a indisciplina demanda profundas investigações e discussões acerca de quais seriam as suas causas e como lidar com o mesmo. 
Especificamente em relação ao Ensino Profissional, verificou-se que há poucas pesquisas acerca da indisciplina neste ambiente, o que se constitui, inclusive, em uma limitação para o presente trabalho, tanto em relação à escassez dos dados apresentados, como, consequentemente, para as conclusões apresentadas.

Porém, compreendo o Ensino Técnico como um espaço em plena expansão, e sendo unânimes os (poucos) trabalhos avaliados no sentido de que a indisciplina ocorre também neste cenário, certo é que a matéria deverá ser objeto de maiores investigações no futuro.

A partir destas observações, pode-se pensar na possibilidade de abrir-se novas investigações. Neste aspecto, se abrem possibilidades para novas pesquisas no que concerne à ocorrência da indisciplina no espaço do Ensino Profissional (de forma integrada ou não ao ensino regular), às causas do fenômeno neste ambiente em particular e em relação à forma como os professores lidam com as condutas indisciplinadas (com vistas inclusive a uma maior preparação dos professores para a gestão das situações de indisciplina).

\section{REFERÊNCIAS}

AQUINO, Júlio R. Groppa. "A desordem na relação professor-aluno: Indisciplina, moralidade e conhecimento". In: AQUINO, Júlio R. Groppa. Indisciplina na Escola alternativas teóricas e práticas. São Paulo: Summus, 1996. p. 39-55.

AQUINO, Júlio R. Groppa. Da (Contra)normatividade do cotidiano escolar: problematizando discursos sobre a indisciplina discente. Cadernos de Pesquisa. vol.41, no.143, pp. 456/484, São Paulo Mai/Ago. 2011. Disponível em <http://www.scielo.br/ scielo.php?script $=$ sci_arttext\&pid=S0100-15742011000200007\&lng $=$ en\&nrm=iso\&tlng $=$ pt $>$, acesso em 30/04/2018.

AQUINO, Júlio R. Groppa. A indisciplina e a escola atual. Revista da Faculdade de Educação, vol. 24, n. 2, São Paulo, p.p. 181-204, jul/1998. Disponível em: <http://www. scielo.br/scielo.php?script $=$ sci_arttext\&pid $=$ S0102-25551998000200011\&lng $=$ pt\&nrm $=\mathrm{i}$ so>, acesso em 06/04/2017.

CARACIOLO, José Igor Souza. O Adolescente e a Indisciplina em sala de Aula. IV Colóquio de História - Abordagens Interdisciplinares, 2010. Disponível em: <http://www.unicap.br/coloquiodehistoria/wp-content/uploads/2013/11/4Col-p.10. pdf>, acesso em 27/01/2018.

CARVALHO, Isabela A. Os desafios do pedagogo na função supervisora em uma instituição de educação profissional. Holos, 2014, 2, p.p. 65-74, ISSN 1518-1634, disponível em: < http://www.redalyc.org/html/4815/481547171008/>, acesso em 09/03/2018.

COUTO, Vânia Sofia Lopes Sengo Freixo de Oliveira. Indisciplina na Escola: Um estudo sobre os comportamentos de (in)disciplina de alunos de cursos profissionais. Repositório Aberto da Universidade do Porto, Porto/Portugal, 
2013, disponível em < https:/ / repositorio-aberto.up.pt/bitstream/10216/71845/2/ tesemestvaniacoutoindisciplina000222520.pdf>, acesso em 09/03/2018.

GARCIA, Joe. Indisciplina, incivilidade e cidadania na escola. ETD - Educação

Temática Digital, Campinas/SP, v. 8, n. 1, p. 10-32, dez. 2006) - ISSN: 1676-2592, disponível em <https://www.ssoar.info/ssoar/handle/document/19764>, acesso em 27/01/2018.

Indisciplina na escola. Joe Garcia. Vídeo publicado no Youtube em 10/05/2013, disponível em <https://www.youtube.com/watch?v=iC6d5NRiYCo $>$, acesso em 08/04/2017.

GUEDES, Annallena de Souza; PAULINO, Eliene de Souza. O ensino e a experiência nas narrativas de professores de Inglês. Revista Principia - Divulgação Científica e Tecnológica do IFPB, [S.1.], n. 30, p. 100-110, set. 2016. ISSN 2447-9187. Disponível em: <http://periodicos.ifpb.edu.br/index.php/principia/article/view/398>. Acesso em: 09/03/2018.

KNOBLAUCH, Adriane. Entre faltas e estrelas: controle e disciplina no processo de socialização profissional de professoras. Perspectiva, Florianópolis, v. 34, n. 2, pp. 654670, maio/ago. 2016, ISSN 2175-795X, disponível em: <https:/ / periodicos.ufsc.br/ index.php/perspectiva/article/view/2175-795X.2016v34n2p654/32794>, acesso em $09 / 03 / 2018$.

OLIVEIRA, Maria Teresa Mateus. GRAÇA, Amândio. Procedimentos dos Professores Relativamente aos Comportamentos de Indisciplina dos Alunos na Aula de Educação Física. Millenium, n. 45. p. 25-43, dezembro/2013.

RODRIGUES, Ícaro Arcênio Alencar. A indisciplina e o regulamento disciplinar: percepções de estudantes de cursos técnicos integrados.

Revista Principia, 2015, 1(27):89-95, disponível em < https://doaj.org/ article/574d3eb65b3543e9bc57e8f979c6ed10>, acesso em 09/03/2018.

RODRIGUES, Ícaro Arcênio Aguiar, GOMES, M. M. C., MARQUES, L. C. Como os docentes de cursos técnicos integrados compartilham a gestão da indisciplina. Holos, Natal, Ano 33, v. 4, p. 171-184, 2017. Disponível em <http://www2.ifrn.edu.br/ojs/ index.php/HOLOS/article/view/3301/pdf>, acesso em 27/01/2018;

SOUZA, Jadir Cirqueira de. Refém da Violência Escolar: Como Reagir? Revista Justitia, Uberlândia, 2007, disponível em < http:/ / revistajustitia.com.br/artigos/1d04db.pdf>, acesso em 27/01/2018.

SOUZA, Marcela Tavares, SILVA, Michelly Dias de, CARVALHO, Rachel de. Revisão Integrativa: o que é e como fazer? Einstein, 2010; 8(1 Pt 1):102-6, disponível em <http://www.scielo.br/pdf/eins/v8n1/pt_1679-4508-eins-8-1-0102>, acesso em 22/03/2018. 
TAILLE, Yves de la. "A indisciplina e o sentimento de vergonha". In: AQUINO, Júlio R. Groppa. Indisciplina na Escola - alternativas teóricas e práticas. São Paulo: Summus, 1996. p. 09-23.

TAVARES, Andrevaldo Glaidson Pereira. O professor diretor de turma como mediador no processo ensino-aprendizagem. Revista Pedagógica, v. 13, n.27, pp. 445-467, jul/ dez. 2011, ISSN 1984-1566, disponível em <https://bell.unochapeco.edu.br/revistas/ index.php/pedagogica/article/view/1316/730>, acesso em 09/03/2018. 